
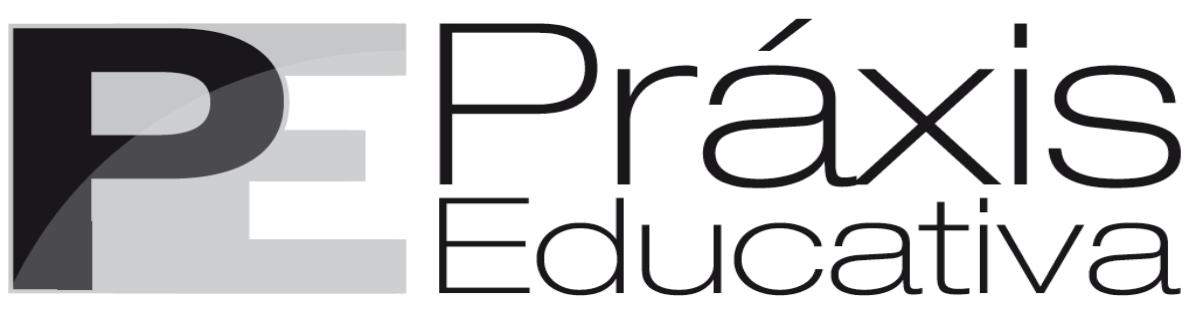

ISSN 1809-4031

elSSN 1809-4309

https://doi.org/10.5212/PraxEduc.v.16.18297.067

\title{
Redes políticas de currículo: a atuação da Fundação Getulio Vargas
}

\section{Curriculum policy networks: Getulio Vargas Foundation's enactment}

\section{Redes políticas de currículo: la actuación de la Fundación Getulio Vargas}

\author{
Hellen Gregol Araujo* \\ (iD) https://orcid.org/0000-0002-1923-9164 \\ Alice Casimiro Lopes** \\ https://orcid.org/0000-0001-9943-9117
}

\begin{abstract}
Resumo: Neste artigo, analisamos mudanças no modo de governança exercido por instituições filantrópicas e privadas na educação, com foco nas redes políticas de Stephen J. Ball. A noção de redes é associada à noção de social como prática discursiva de Ernesto Laclau, fazendo-nos conceber tais redes como espaços de disputa nas políticas educacionais e como representação do social, jamais plena, mas produtiva para interpretar a influência de instituições nas decisões políticas. Como exemplo dessa análise, focalizamos o protagonismo da Fundação Getulio Vargas (FGV), após a homologação da Base Nacional Comum Curricular (BNCC), em busca de evidenciarmos sua atuação, inclusive internacional, nas ações de "implementação" da BNCC e na constituição de "novos" processos de gestão privada da educação pública. Palavras-chave: Política de currículo. Redes políticas. Fundação Getulio Vargas. Base Nacional Comum Curricular. Discurso.
\end{abstract}

\begin{abstract}
In this article, we analyze changes in the mode of governance exercised by philanthropic and private institutions in education, with a focus on the policy networks of Stephen J. Ball. The notion of networks is associated with Ernesto Laclau's notion of social as discursive practice, making us conceive these networks as spaces of dispute in education policies and as representation of the social, but never on the whole, but productive to interpret the influence of institutions in political decisions. As example of this analysis, we focused on the protagonism of the Getulio Vargas Foundation (FGV), after the approval of the National Curriculum Common Core (Base Nacional Comum Curricular - BNCC), seeking to highlight its enactment, including international, in the "implementation" actions of the BNCC and in the constitution of "new" processes of private management of public education.

Keywords: Curriculum policy. Policy networks. Getulio Vargas Foundation. National Curriculum Common Core. Discourse.

\footnotetext{
${ }^{*}$ Doutoranda em Educação - ProPed - Universidade do Estado do Rio de Janeiro (Uerj). Bolsista pela Fundação de Amparo à Pesquisa do Estado do Rio de Janeiro (Faperj). E-mail: <hellengre@gmail.com>.

** Professora Titular da Faculdade de Educação da Universidade do Estado do Rio de Janeiro (Uerj). Doutora em Educação pela Universidade Federal do Rio de Janeiro. Bolsista PQ 1A do Conselho Nacional de Desenvolvimento Científico e Tecnológico (CNPq), Cientista do Nosso Estado Faperj e Procientista Faperj/Uerj. Este trabalho conta também com o apoio do Programa da Coordenação de Aperfeiçoamento de Pessoal de Nível Superior - Capes PrInt. E-mail: <alicecasimirolopes@gmail.com>.
}

Práxis Educativa, Ponta Grossa, v. 16, e2118297, p. 1-18, 2021 Disponível em: <https:// revistas2.uepg.br/index.php/praxiseducativa $>$ 
Resumen: En este artículo analizamos los cambios en el modo de gobernanza ejercidos por instituciones filantrópicas y privadas en la educación con enfoque en las redes políticas de Stephen J. Ball. La noción de redes está asociada a la noción de social como práctica discursiva de Ernesto Laclau, haciéndonos concebir tales redes como espacios de disputa en las políticas educativas y como representación de lo social, jamás plena, pero productiva para interpretar la influencia de instituciones en las decisiones políticas. Como ejemplo de este análisis, enfocamos en el protagonismo de la Fundación Getulio Vargas (FGV), luego de la homologación de la Base Nacional Común Curricular (BNCC), en busca de evidenciar su desempeño, incluso internacional, en las acciones de "implementación" de la BNCC y en la constitución de "nuevos" procesos de gestión privada de la educación pública.

Palabras clave: Política de Currículo. Redes políticas. Fundación Getulio Vargas. Base Nacional Común Curricular. Discurso.

\section{Introdução}

Há algum tempo se questiona, no Brasil, a opção de projetar uma base curricular nacional voltada a conteúdos concebidos como essenciais e/ou universais, tendo em vista essa base ter sido resultado da articulação de demandas vinculadas às metas instrucionais e demandas associadas às metas de justiça social via distribuição de conhecimento. Tais lutas não se apartam de um movimento globalizado - de forma sempre ressignificada e conflituosa, nunca mero reflexo de interesses e propostas - capaz de contribuir para hegemonizar a necessidade de o Brasil criar padrões de aprendizagem (BANCO MUNDIAL, 2018). Na perspectiva desse movimento global, uma base comum favoreceria docentes e alunas/os estarem cientes do que precisaria ser aprendido e, consequentemente, garantiria o direito à aprendizagem dos estudantes. Na afirmação, por exemplo, do Banco Mundial (2018), a falta de clareza de qual conhecimento deve ser priorizado pode ser um dos motivos pelo qual os estudantes brasileiros estão abaixo das expectativas de aprendizagem nacionais e internacionais.

Desde a definição, inserida na Constituição Federal de 1988, de conteúdos mínimos visando uma formação básica nacional comum até o registro, no Plano Nacional de Educação (PNE) (BRASIL, 2014), de um prazo de dois anos para produção de uma Base Nacional Comum Curricular (BNCC), muitas foram as lutas políticas em torno da ideia de base curricular (AGUIAR, 2018) e muitas outras foram as demandas inseridas nessa articulação (MACEDO, 2014). Nesse movimento de ampliação de demandas, tornadas equivalentes em nome da qualidade da educação (MATHEUS; LOPES, 2014), tornou-se crescente o número de instituições privadas e filantrópicas que passaram a investir recursos pessoais e financeiros para apoiar a elaboração da BNCC e, de diferentes formas, apoiar sua difusão e "implementação" .

\footnotetext{
1 Utilizamos o termo implementação entre aspas, porque entendemos que esse termo não expressa devidamente o efeito das formulações políticas no contexto da prática (LOPES; MACEDO, 2011). Salientamos, contudo, que retiramos essas aspas quando nos referimos à forma como os movimentos pela Base vêm trabalhando por sua implementação, uma vez que esses movimentos operam com uma separação proposta-prática e concebem a leitura e a incorporação da BNCC nas escolas como a implementação de um projeto previamente definido, sem traduções ou reinterpretações, ou ao menos em relações de poder que devem sim limitar tais traduções e reinterpretações.
}

Práxis Educativa, Ponta Grossa, v. 16, e2118297, p. 1-18, 2021 
Dois exemplos sempre lembrados são os movimentos Todos pela Educação ${ }^{2}$ e Movimento Todos pela Base ${ }^{3}$.

Em defesa da necessidade de "orientar os professores", é reiterado que os documentos homologados são extensos e estão organizados de forma a gerar dúvidas, tornando importante, do ponto de vista dessas organizações, produzir orientações para que, nas palavras de Cleuza Repulho $(2019,34 \mathrm{~min})^{4}$, “[...] não [se] cometa o erro de mandar todos os professores lerem toda a base, são 600 páginas, você vai ter um exército de pessoas odiando a base”.

Essas instituições e esses movimentos destacaram-se inclusive por criar o Movimento todos pela Base ${ }^{5}$, patrocinando viagens aos secretários da educação (AVELAR; BALL, 2017), investindo em eventos pró-BNCC e difundindo propostas curriculares para as secretarias ou diretamente para os docentes. Como já demonstrado nas pesquisas de Avelar e Ball (2017) e Tarlau e Moeller (2019), há um protagonismo da Fundação Lemann nessas ações - "[...] os funcionários da Fundação Lemann receberam cópias da terceira versão do BNCC antes de ser publicado" (TARLAU; MOULLER, 2019, p. 22) -, fazendo com que muitos já tenham se dedicado à investigação das ações dessa fundação no Brasil (AVELAR; BALL, 2017; ROSA; FERREIRA; SILVA, 2020).

Destacamos a importância das investigações sobre a atuação da Fundação Lemann. Todavia lembramos que esse destaque não deve obscurecer a ação significativa de outros atores sociais (agentes individuais e instituições) e, sobretudo, a ampliação de seu poder em função da ação dessas instituições em redes políticas. A partir de uma pesquisa mais ampla das redes que atuam na produção da BNCC, foi possível identificarmos, por meio da etnografia de redes (BALL, 2014), outras instituições que intensificam as relações de força umas com as outras. Para este artigo, em particular, destacamos o protagonismo da Fundação Getulio Vargas (FGV), principalmente após a homologação da Base, considerando essa fundação menos focalizada ${ }^{6}$ nas investigações sobre políticas curriculares.

No início de 2021, a Universidade da Pensilvânia avaliou, por meio de uma pesquisa (MCGANN, 2021), quais eram as instituições mais influentes do mundo. A FGV ganhou o título de terceira think tank $k^{7}$ mais importante do mundo. Nessa pesquisa, foi considerado o poder de influência na dinâmica e na orientação das políticas públicas, levando em conta as respostas às

\footnotetext{
2 Em 2006, esse movimento surgiu, se afirmando como um movimento da sociedade civil, apartidário, preocupado somente com a educação. É financiado por empresas, e, atualmente, Priscila Cruz é presidente-executiva e cofundadora, fez Administração de Empresas pela Fundação Getulio Vargas e tem experiência com o Terceiro Setor, ajudou a fundar o Instituto Faça Parte. Como diretor-executivo, Olavo Nogueira Filho, formado em Administração pela Universidade Notre Dame, nos Estados Unidos da América (EUA).

3 O Movimento Todos pela Base existe desde 2013 e é uma iniciativa da Fundação Lemann com outras instituições que visam manter o debate e promover a BNCC.

${ }^{4}$ Ex-presidente da União Nacional dos Dirigentes Municipais de Educação (Undime), foi dirigente municipal de Santo André e de São Bernardo do Campo (SP) na gestão de Luiz Marinho, filiado ao Partido dos Trabalhadores. Atualmente é consultora de Educação, da Fundação Lemann e Instituto Arapyau. Em 2018, foi consultora da Fundação Getulio Vargas e do Instituto Natura.

5 Algumas dessas instituições são: Instituto Inspirare, Fundação Ayrton Senna, Fundação Lemann, Instituto Natura, Instituto Unibanco, Fundação Roberto Marinho, Fundação Maria Cecilia Souto Vidigal.

${ }^{6}$ Não foi encontrado nenhum artigo sobre a instituição FGV como protagonista no debate das políticas educacionais e curriculares ao pesquisar a palavra Fundação Getulio Vargas nas plataformas de Periódicos da Capes e da Biblioteca Eletrônica Científica Online (SciELO).

7 Think tanks é um termo usado para instituições e agentes individuais que organizam pesquisas e propostas de soluções na área social e política, visando a influência em políticas públicas. A pesquisa Global Go To Think Tank Index Report (MCGANN, 2021), da Universidade da Pensilvânia, visou analisar a evolução do papel dessas organizações em relação às políticas públicas.
}

Práxis Educativa, Ponta Grossa, v. 16, e2118297, p. 1-18, 2021 Disponível em: <https:// revistas2.uepg.br/index.php/praxiseducativa $>$ 
questões sociais e o incentivo às políticas públicas. Nos últimos 11 anos, a instituição foi classificada também como a mais influente na América Latina e, nos últimos cinco anos, a mais bem administrada do mundo (MCGANN, 2021).

A proposta deste artigo é então explorar a posição da FGV nesta ampla rede de apoio à BNCC: quem são seus parceiros, quais suas propostas, a forma como vem atuando na luta para constituir discursos curriculares por meio de seus eventos, docentes e coordenadores. O material investigado foi obtido via Internet, em sites oficiais e nas mídias sociais das instituições envolvidas. Procuramos explorar as ramificações desses movimentos e instituições que vêm inserindo sentidos na luta política discursiva que constitui e busca hegemonizar a BNCC.

A etnografia de redes é aqui inspirada nos estudos de Ball (2014) e Ball e Junemann (2012) com políticas educativas. Em tempos passados, Ball e Bowe (1992) exploraram, com a abordagem do ciclo de políticas, a política via contextos, por vezes analisados separadamente, tendo recebido críticas por priorizar o contexto de influência em relação ao contexto de definição de textos e o contexto da prática (LOPES; MACEDO, 2011). Sem abandonar a noção de ciclo de políticas, Ball (2014) complexifica o entendimento das políticas educativas no mundo global ao incorporar a noção de redes em novos modos de interpretar essas políticas.

$\mathrm{Na}$ interpretação aqui apresentada sobre a etnografia de redes, incorporamos a compreensão do social como discursivo, desprovido de um centro ou de uma estrutura determinada capaz de fixar sua identidade (LACLAU, 2011). Do ponto de vista estratégico mais imediato, a consequência desse enfoque pós-estrutural é a não redução da política às determinações econômicas do capital ou mesmo às ações de agentes governamentais ou das agências multilaterais. Nessa expansão significativa do modo de interpretar o desenvolvimento da política, tais determinações e agentes não são desconsiderados, mas sua ação é inserida na formação de uma rede política de produção de sentidos. Para tal, apoiamo-nos na etnografia de redes de forma articulada a um enfoque discursivo da política de currículo (LOPES, 2018; MACEDO, 2014).

O objetivo da articulação teórica de Ball com a teoria do discurso (LACLAU, 2011) é o de compreender a rede política que possibilita discursos se sedimentarem criando uma realidade suposta como irrefutável. Afastamo-nos da distinção feita por Ball (2015) entre política como texto a ser lido de forma aberta, passível de tradução, e política como discurso, como estrutura de significação que limita tanto essa leitura aberta quanto sua tradução. Diferentemente, operamos com a política como discurso, por entendermos que o discurso, ao mesmo tempo em que possibilita sua leitura e tradução, constrange o texto. O texto torna-se performativo, sem haver distinção, inclusive, entre teoria e prática: o texto é prática discursiva. Desse modo, também visamos nos afastar das críticas a uma possível boa concepção de política, porém mal implementada (BALL; MAGUIRE; BRAUN, 2016). A política não é implementada, mas se desenvolve contextualmente por sucessivas traduções atinentes à linguagem (LOPES, 2018). A esfera de disputa e de desenvolvimento da política, igualmente, não possui uma margem específica, em que possa ser mensurado seu começo e fim. Múltiplas são as políticas inter-relacionadas visando a determinadas finalidades e a formação discursiva de identidades. Nesse sentido, não cabe aqui nenhum julgamento moral das instituições e das pessoas atuantes na política. Nosso foco é o entendimento dos efeitos produzidos nas políticas curriculares pela ação dessas pessoas e instituições, considerando tais sujeitos como discursivamente produzidos.

Nesse processo, a ascensão das instituições privadas e filantrópicas nessas redes de discursos vem sendo cada vez mais destacada. Nas mais recentes discussões sobre políticas educacionais, vêm sendo discutidas as mudanças no modo de governança, com desdobramentos na produção curricular, gerados pelas políticas em rede. A desejada autonomia das escolas na elaboração de seus currículos está sendo substituída por planos de aula e guias disponibilizados

Práxis Educativa, Ponta Grossa, v. 16, e2118297, p. 1-18, 2021 Disponível em: <https:// revistas2.uepg.br/index.php/praxiseducativa $>$ 
pelas instituições privadas e fundações filantrópicas, fora de ações usualmente entendidas como instituídas pelo poder público. Como mencionam Avelar e Ball (2017), em outros tempos, as políticas públicas eram planejadas principalmente no âmbito governamental, predominando um processo hierárquico: o poder de determinados cargos garantia maior influência em como a política era desenvolvida. Para Ball (2014), atualmente há um deslocamento para relações heterárquicas, nas quais o poder não está reduzido ao setor público ou aos cargos políticos: pesam não somente o poder legítimo do Estado em espaços formais de formulação de políticas, mas o poder dos atores sociais que financiam a política de diferentes modos. Dessa maneira, no conjunto de proposições para a política, o que acontece fora desses espaços formais passa a ter maior relevância e precisa ser considerado para melhor compreensão do funcionamento das políticas públicas. Como sinalizam Lima e Hypólito (2020), ao investigarem as redes de atores sociais associadas ao movimento Escola sem Partido, novos espaços de governança heterárquicos se mostram como reflexivos, autorregulados e horizontais.

Emerge, assim, uma prática de pesquisa da política por meio de redes, visando a identificar tais processos heterárquicos em ação, bem como a manutenção e a evolução das redes políticas. A análise por redes considera importante investigar como uma política é posta em atuação, mas também onde e como é difundida, destacando eventos, promovidos ou não pelas instituições públicas, que objetivam discutir as políticas públicas e acrescentar posicionamentos favoráveis ou contra às ações públicas. Tais processos se internacionalizam e se inserem na lógica dos processos globais, ganhando força nessa relação. Para desenvolvimento desse argumento, inicialmente exploramos as mudanças sociais que desencadearam novos modos de interpretar a política por redes. Posteriormente, exploramos a opacidade entre público e privado e o deslocamento das soluções para os problemas educacionais, apresentando a rede política na qual se insere a FGV.

\section{Redes políticas: globalização e as redes neoliberais de governança}

Ball (2014) e Ball e Junemann (2012) mapeiam redes políticas, em diferentes países, e apostam nas redes para entenderem a complexidade do social que já não pode ser reduzido a um governo ou às relações hierárquicas: seu foco está nos "modos neoliberais de governança" (AVELAR; NIKITA; BALL, p. 56, 2018, tradução nossa).

Governança refere-se a um novo processo de governar realizado por meio da "autoridade informal" de redes diversas e flexíveis, em que o Estado não está sumindo, mas se reinventando, deixando de ser um governo realizado por meio de hierarquias ou especificamente dentro de administrações e por métodos burocráticos (BALL; JUNEMANN, 2012). As relações heterárquicas são decorrentes desses novos modos de governar. Como discutido por Cóssio e Scherer (2018, p. 140), “[...] o conceito de governança dá suporte às alterações do papel do Estado em escala global, exprimindo procedimentos e práticas governamentais relevantes ao processo decisório", incorporando tanto o chamado novo gerencialismo quanto uma concepção estatal pluricêntrica.

O deslocamento da centralidade no Estado para as empresas privadas e filantrópicas exigiu, dos pesquisadores interessados em compreenderem as políticas educacionais, um novo modo de investigar esse social. Admitir que as políticas não são feitas somente nos setores formais da nossa sociedade, como as ações do Executivo e do Legislativo, implica investigar como as redes estão se constituindo, como apresentam seus projetos, em quais espaços, atividades, com quais pessoas e instituições (públicas, privadas e/ou filantrópicas). A política acontece, também, e às vezes principalmente, nos eventos sociais, nas trocas de e-mails e mensagens nas redes sociais e em encontros cotidianos que, muitas vezes, não podem ser mapeados. Importa também investigar a

Práxis Educativa, Ponta Grossa, v. 16, e2118297, p. 1-18, 2021

Disponível em: <https:// revistas2.uepg.br/index.php/praxiseducativa $>$ 
produção de materiais para serem vendidos às instituições públicas objetivando, no caso da política em pauta, que as escolas saibam implementar a BNCC.

$\mathrm{Na}$ análise de Ball e Junemann (2012), a etnografia de redes é uma tentativa de entender o neoliberalismo na prática. Tal forma distinta de investigar envolve igualmente uma ressignificação do termo neoliberalismo. Para Ball (2014), o neoliberalismo refere-se a algo complexo, principalmente pelos seus efeitos: "[...] neoliberalismo é sobre dinheiro e mentes, e como eu seguirei argumentando é um nexo de interesse comum entre as várias formas de capital e de Estado contemporâneos" (BALL, 2014, p. 26). Por mais que nos posicionemos contra o neoliberalismo, principalmente por ser uma doutrina econômica que traz uma visão restrita e onipotente de mercado para os projetos políticos, não pode ser negado que, em alguns casos, ele também oferece educação para áreas nas quais o Estado negligencia atenção, fazendo com que, desse modo, sua força discursiva se amplie (BALL, 2014). Isso não significa ser a favor do neoliberalismo, mas ter cuidado no modo como argumentamos contra suas ações e, sobretudo, seus efeitos, já que "trazem "soluções" privadas e filantrópicas para os "problemas" da educação pública" (BALL, 2014, p. 25).

Pereda (2019), por exemplo, analisa a influência de fundações nas políticas do Uruguai e aponta algo que pode ser uma questão também para o Brasil: as fundações apresentam-se como especialistas diante das incertezas do Estado. Mesmo após diagnósticos, constatações da suposta "ineficiência da educação", as políticas seguem reiterando o que já foi mencionado em políticas anteriores. Isso abre espaço para que um discurso de falta de eficiência em resolver os problemas educacionais (PEREDA, 2019) possa ser instituído, favorecendo aqueles que desejam vender supostas soluções para tais problemas. De certa forma, é nesse contexto que surge a ascensão do apoio das instituições privadas e sua aproximação com o Estado: tanto formulam o diagnóstico da ineficiência quanto apresentam a solução a ser construída para "resolver" essa mesma ineficiência por eles diagnosticada. Acrescente-se a isso o fato de que tais diagnósticos são baseados em estatísticas educacionais tratadas como inquestionáveis, uma vez que os estudos sobre as limitações teóricas e técnicas dessas estatísticas tendem a ser desconsiderados (LOPES; MACEDO, 2021).

Em relação aos mecanismos de identificação dessas redes, Ball (2014) e Ball e Junemann (2012) destacam a importância de um olhar para os curricula vitae dos atores sociais envolvidos nas políticas. Por eles, é possível identificar a permeabilidade das relações entre público e privado; como os atores sociais transitam de um cargo público para uma instituição privada ou filantrópica e vice-versa; quais os mecanismos de interação desenvolvidos por meio de eventos, reuniões, seminário, cursos, viagens. As redes são, assim, meios para tentar rastrear e representar as relações turvas no campo da política, uma ferramenta analítica com nuances, "[...] uma espécie de interior confuso que suplementa e às vezes subverte essas outras formas" (BALL; JUNEMANN, 2012, p. 21, tradução nossa). Nas palavras de Avelar, Nikita e Ball (2018, p. 56, tradução nossa): "Isto levou a um afastamento dos sistemas de governo centrados no Estado em direção a uma forma heterárquica que depende de redes de atores (instituições e agentes individuais) ativamente envolvidos em processos de formulação de políticas". Ainda assim, Ball menciona a dificuldade de mapear empiricamente as relações de poder, por isso ele se refere a um processo exaustivo que não pode ser reduzido a uma notícia ou a uma informação específica: é um movimento que se repete e se apresenta de diferentes modos.

A tentativa desta pesquisa foi então o de deslocar a prática investigativa para outros espaços nos quais a política está sendo realizada e governada, identificando possíveis atores sociais que participam das articulações políticas nesses espaços. O foco não está em estruturas sociais fixas e pré-definidas, mas nos fluxos e nas mobilidades (BALL, 2014), na prestação de serviços e na venda de soluções para os problemas educacionais, nas ações que constituem esse novo modo de governança exercido por instituições privadas e filantrópicas para o Estado, destacando as

Práxis Educativa, Ponta Grossa, v. 16, e2118297, p. 1-18, 2021 Disponível em: < https://revistas2.uepg.br/index.php/praxiseducativa $>$ 
empresas que “[...] estão agora diretamente envolvidas com política educacional em uma série de maneiras diferentes, esses compromissos (que) são parte de um conjunto mais amplo de processos complexos que afetam a política educacional” (BALL, 2014, p. 37).

Vale destacarmos que, por meio da etnografia de redes pró-BNCC, também é possível identificar "comunidades epistêmicas" (BALL, 2014, p. 108). As comunidades epistêmicas são constituídas por sujeitos que atuam politicamente em nome de um saber, diagnosticam e comercializam soluções em nome dessas relações saber-poder (DIAS; LOPES, 2009). As comunidades epistêmicas também atuam na produção e na disseminação de textos, na circulação dos discursos, por meio de materiais, eventos, cursos. Nos tempos atuais, a Internet e as redes sociais têm auxiliado ainda mais na disseminação dessas ideias. Tais comunidades incluem não apenas os think tanks (ver nota 7), mas também, por exemplo, empresários que investem tempo e dinheiro para convencer profissionais da educação de que os alunos precisam aprender determinados conhecimentos, com base na ideia de que, somente assim, direitos até então negados, serão garantidos. As comunidades epistêmicas atuam em nome de um pretendido saber especializado, suposto como capaz de gerenciar grandes sistemas e resolver problemas, apresentado como apartado dos antagonismos e das lutas políticas. Trata-se de uma ação de poder tão mais efetiva quanto mais essa ação de poder é negada.

Nesse cenário, as redes pró-BNCC mostram-se preocupadas em disponibilizar materiais que possam ser acessados pelos professores, a fim de difundir os padrões capazes de garantir uma "implementação adequada" para fazer valer direitos considerados negados, como: aprendizagem, educação de qualidade, conhecimento, justiça social, respeito à diferença, diversidade, acesso às novas tecnologias. Nesse jogo político, atores sociais disputam significações e sentidos para esses direitos, a partir da articulação de demandas em amplas cadeias de equivalência (im)possibilitadas pelo antagonismo (LACLAU, 2011) a tudo e todos que, pelo diagnóstico em jogo, sustentam a ineficiência da educação e impedem a qualidade da educação. É reiterado que instituições, fundações e movimentos oferecem soluções para uma educação que já não responde às necessidades do nosso tempo (BRASIL, 2018). Contudo, tais propostas disponibilizadas só serão consideradas eficientes suficientemente, no dizer dessas mesmas redes, se os professores estiverem preparados. Tal entendimento sustenta uma ampla gama de guias, livros e planos lançados em eventos a fim de explicar a BNCC aos professores, buscando criar um consenso sobre a necessidade de apoio à política de centralização curricular.

Como amplamente reconhecido, as mudanças referentes às formas de governança estão envolvidas em processos globais (VERGER, 2019). O alcance de instituições internacionais como a Fundação Bill Gates, que financiou e apoiou o Commom Core do currículo estadunidense, mencionado durante palestra (YOUNG, 2014) como um modelo de sucesso no qual o Brasil deve se inspirar, tem atuação expressiva na internacionalização e na movimentação dessa rede em âmbito global. Essa Fundação é um dos atuais think tanks que afirma preferir criar suas próprias soluções a investir dinheiro em soluções de outras instituições, dentre elas as governamentais. De 2017 a 2022, a fundação estima investir US\$1,7 bilhão em educação pública (WAN, 2020).

De acordo com Tarlau e Moeller (2019), parte desse movimento visível das instituições privadas e filantrópicas na educação foi legitimado pela ONU, eles se engajaram, "[...] permitiram e legitimaram o movimento de corporações, fundações corporativas e filantrópicas privadas no campo de desenvolvimento e educação, vinculando os discursos de responsabilidade social corporativa e educação para todos" (TARLAU; MOULLER, 2019, p. 4, tradução nossa).

Reiteramos não ser possível desvincular o poder do dinheiro. É perceptível que algumas políticas têm maior investimento do que outras, mas tal investimento, para se sustentar, depende de se articular mais amplamente a diferentes demandas (LACLAU, 2009) e constituir discursos de

Práxis Educativa, Ponta Grossa, v. 16, e2118297, p. 1-18, 2021

Disponível em: <https:// revistas2.uepg.br/index.php/praxiseducativa $>$ 
justificativa e de promessa de resultados capazes de sustentar tais investimentos. A circulação desse dinheiro se faz então por meio de práticas discursivas que legitimam e constituem um modelo educacional no qual os investimentos financeiros, afetos e ações são mobilizados. Assim, as forças que movem as políticas educacionais globalmente são privilegiadas por investimentos financeiros em tecnologias, eventos, viagens, financiados, na maior parte das vezes, por tais instituições. $\mathrm{O}$ investimento faz com que tais instituições se tornem atores sociais importantes no momento de escolha do conhecimento a ser priorizado na formulação da política. Como Ball (2014) menciona, processos de metagovernança, em que as condições de governança se ampliaram e se associaram aos objetivos do Estado, criam um complexo de interdependência público-privado.

Esses novos parâmetros também constituem o que Ball (2014) cita como a terceira onda, em referência ao neoliberalismo roll-back e roll-out. Para o autor, é possível ver esse movimento "[...] dentro dessas redes, como antes, também é possível ver a interação prática entre o neoliberalismo roll-back (crítica à educação do setor público) e roll-out (novas oportunidades de negócios nos serviços públicos)" (BALL, 2014, p. 193). Ademais, a regulação está associada ao objetivo de que um país participe de forma eficaz nos movimentos globais, de modo a se tornar competitivo o suficiente no exterior.

As novas oportunidades de negócio globais nos serviços públicos se estabelecem localmente, fazendo com que a incorporação da política no âmbito local faça parte da manutenção da rede e dos efeitos da globalização. Existe assim um movimento difuso entre processos de globalização e de localização. A globalização das políticas não fica restrita às orientações dos organismos internacionais, ainda que estes façam parte das diretrizes para os países que buscam um desenvolvimento perante o mundo, o que inclui apresentar dados estatísticos como indicadores de sucesso para competir por melhores oportunidades internacionalmente. A globalização assume também uma dimensão discursiva, pela qual se conclui que nenhum discurso pode se localizar se não se articular com outros discursos, tornando inescapável sua tradução e a formação de híbridos culturais (RIVZI; LINGARD, 2013).

Mouffe (2015) identifica a globalização como a pretensão de universalização da democracia liberal como "o futuro que trará paz" e a implementação dos direitos humanos que está sempre por vir. Desse modo, a política, restrita ao nível ôntico, envolve tentativas de apagar o conflito constitutivo do político referente à dimensão antagônica das relações políticas (MOUFFE, 2015). Isso envolve desestimular a negociação constante em qualquer política. A globalização na educação apresenta-se, assim, como um processo heterogêneo, produzido pela movimentação política de organizações, empresas, instituições públicas e privadas que investem em ideias supostas como capazes de solucionar os problemas educacionais, tendo relação direta com a construção de redes internacionais. Por meio dessas redes, discursos circulam e são produzidos, em um processo de difusão, com efeitos de poder. Parte do sucesso da difusão/infusão das instituições ocorre devido às instituições públicas aceitarem os investimentos e os discursos desses movimentos, tornando opacas as diferenças entre discursos públicos e privados por aprendizagem, tecnologia, qualidade da educação.

Operamos com essas redes constituídas por instituições e agentes individuais como redes discursivas, nas quais as instituições são discursos que produzem identidades/subjetividades e, ao mesmo tempo, produzem a leitura da realidade. Isso não impede que consideremos importante, no trabalho com as redes políticas, identificar atores sociais significativos no encaminhamento da política educacional brasileira. Defendemos que a mera troca das pessoas e das instituições envolvidas em uma política não altera a constituição discursiva dessa política, a articulação de demandas que produz tais discursos políticos. Todavia, conhecermos quem são os agentes dessa

Práxis Educativa, Ponta Grossa, v. 16, e2118297, p. 1-18, 2021

Disponível em: <https:// revistas2.uepg.br/index.php/praxiseducativa $>$ 
política hoje nos parece ser produtivo para as lutas políticas que buscam favorecer os diferimentos, as novas hegemonias, os escapes e as fraturas nos discursos hegemônicos.

A etnografia de redes pode ser inclusive uma tentativa de interpretarmos as demandas educacionais locais e globais articuladas na política educacional. É também uma tentativa de entendermos como tais demandas se articulam com demandas governamentais por poder. O Brasil tem interesse em ocupar, por exemplo, um cargo na Organização para a Cooperação e Desenvolvimento Econômico (OCDE); há algum tempo vêm pleiteando o apoio dos EUA na indicação a uma cadeira na organização (LÔBO, 2019). Os desdobramentos da ascensão de setores diversos na formulação de políticas públicas é parte de um movimento complexo de mudanças neoliberais que contribui para a ocupação desses postos de poder.

Se pensarmos que a política é um terreno de disputa que não pode ser reduzido a um espaço físico, e o político não pode ser reduzido a um jogo no Legislativo e no Executivo, a lógica da governança é ampliada para outros tempos-espaços. A onda de mudanças no encaminhamento e na governança das políticas educacionais que Ball vem identificando, também identificável no caso da BNCC no Brasil, tende a se afastar da proposta da escola como produtora de currículo e deslegitima o professor como atuante no processo de tradução da política. Tal deslegitimação pode ser desenvolvida mesmo quando associado a um discurso de protagonismo docente. Ao mesmo tempo, as instituições privadas e filantrópicas ganham terreno e firmam seu papel investindo na produção da política curricular para as escolas e mesmo no lugar das escolas.

\section{Instituições privadas e filantrópicas que avançam na BNCC: o caso da FGV}

A trajetória da FGV como instituição que qualifica pessoas para gestão pública não é uma novidade. Nomes importantes na gestão pública do Brasil fizeram Graduação, Pós-Graduação ou cursos de curta duração na FGV, entre eles: Carlos Alberto Decotelli ${ }^{8}$, Claudia Costin", Graça Foster $^{10}$, José Henrique Paim ${ }^{11}$, para citar apenas as referências mais atuais que continuam influenciando nas tomadas de decisão das políticas públicas. Pela atuação de muitas dessas pessoas nessa instituição, a FGV vem ganhando protagonismo no cenário pós-homologação da BNCC.

Para identificarmos a ação dessa instituição na rede pró-implementação da BNCC, investigamos os sites oficiais da FGV e demais instituições pró-BNCC, mas também mídias sociais como o Twitter. Também exploramos eventos disponíveis nos canais do YouTube referentes à política da BNCC, no período de 2014 a 2020. Procuramos vincular notícias, eventos, agentes individuais e seus currículos, instituições participantes, sempre atentas para o fato de que a rede desenvolvida por meio dessas vinculações é parte de uma rede maior que vem influenciando nas

\footnotetext{
${ }^{8}$ Professor colaborador da FGV. Ele assumiu o Ministério da Educação (MEC) por cinco dias. Após envolvimento em polêmicas sobre falsas declarações em seu currículo, pediu exoneração do cargo.

${ }^{9}$ Claudia Costin é professora visitante na Faculdade de Educação de Harvard e Diretora Geral do Centro de Excelência e Inovação em Políticas Educacionais da FGV do Rio de Janeiro. Integra também a Comissão Global sobre o Futuro do Trabalho da Organização internacional do Trabalho (OIT), uma agência das Nações Unidas, e ainda, representa a FGV no conselho do Movimento pela Base. Suas posições anteriores incluem a de Secretária-Executiva e Ministra da Administração e Reforma do Estado durante o governo Fernando Henrique Cardoso (entre 1995 e 2000). Também ocupou o cargo de Secretária de Cultura do Estado de São Paulo durante a primeira gestão de Geraldo Alckmin (PSDB) como governador, entre 2003 e 2005, e Presidente da Promon-Intelligens, empresa voltada ao e-learning. Trabalhou também como consultora em políticas públicas e modernização do Estado, apoiando diversos países africanos como Angola, Cabo Verde, Guiné Bissau Moçambique e São Tomé e Príncipe.

${ }^{10}$ Ex-presidente da Petrobrás, ele cursou Master in Business Administration (MBA) pela FGV-RJ.

11 Atualmente é professor da FGV EBAPE, consultor em Educação do Banco Interamericano de Desenvolvimento (BID) e diretor do Centro de Desenvolvimento da Gestão Pública e Políticas Educacionais da FGV (FGV DGPE).
}

Práxis Educativa, Ponta Grossa, v. 16, e2118297, p. 1-18, 2021 
tomadas de decisão das políticas públicas educacionais e curriculares. As vinculações são estabelecidas por pessoas que se reúnem em eventos e pelas parcerias declaradas oficialmente nas páginas das instituições pesquisadas e, também, analisam os currículos pessoais, os quais mencionam onde essas pessoas já trabalharam.

O material que permitiu constituir especificamente a rede criada para representar a FGV foi levantado após a homologação da BNCC em 2017. Os aspectos considerados foram: nomes de pessoas que ocupam cargos na gestão pública e que têm passagem pela FGV, seja como funcionário ou aluno; o levantamento dos eventos/palestras produzidos pela instituição; as parcerias firmadas para elaboração de projetos a serem compartilhados com os alunos e docentes das redes de ensino; o envolvimento com outras instituições para divulgação e promoção de projetos.

Em muitos dos eventos aqui mapeados, é resgatada a visão de currículo por competências. Não basta garantir os conteúdos a serem ensinados, mas conectar tais conteúdos - reduzidos à noção de conhecimento a ser ensinado - com a formação de competências e garantia das habilidades necessárias à aplicação em contextos pré-definidos (LOPES, 2015). Tais competências e habilidades seriam, então, capazes de garantir melhores resultados de aprendizagem nas avaliações nacionais e internacionais. No evento "Construção da Proposta Curricular no Território do Rio de Janeiro: como fazer o currículo chegar à sala de aula", sobre a implementação da BNCC no Estado do Rio de Janeiro, Lina Vasconcelos mencionou a importância de uma metodologia de ensino, a fim de garantir que os alunos atingissem as 10 competências previstas na BNCC (BRASIL, 2018), apostando nas metodologias ativas.

A FGV tem diversos setores e linhas de atuação. Destacamos quatro deles: Escola Brasileira de Administração Pública e de Empresas da FGV (FGV EBAPE), FGV Ensino Médio, Centro de Desenvolvimento da Gestão Pública e Políticas Educacionais da FGV (FGV DGPE) e a Escola de Economia de São Paulo da FGV (FGV EAESP). Esses núcleos da FGV estão envolvidos diretamente na condução da BNCC. A EBAPE é constituída por três centros: Centro de Pesquisas Comportamentais (CBR), Center for Banking and Finance Research (CBFR) e Centro de Excelência e Inovação em Políticas Educacionais (CEIPE).

O CEIPE é o principal responsável pelas pesquisas e eventos que colaboram para o incentivo das políticas. Esse centro atua como participante ativo por meio dos principais movimentos e fundações que apoiam a BNCC. Além disso, está começando a desenvolver seus próprios projetos em relação à base, afirmando ter por objetivo garantir boa gestão pública e influência na formação adequada dos professores, com um trabalho que leva em conta o fato de que "[...] atraímos apenas os alunos mais fracos no ensino médio para profissão de professor" (COSTIN, 2019, 8min).

Outro destaque é O Conselho Alumni, criado com o objetivo de contribuir para o direcionamento estratégico da EBAPE, a fim de que ela se desenvolva continuamente e atue no aprimoramento da pesquisa e da prática em administração ${ }^{12}$. Na prática, o Conselho afirma estabelecer uma relação de seus egressos com "o mercado", incentivando a atuação em organizações consideradas relevantes. Por meio dessa relação, o Conselho tenta aumentar a sinergia entre a Fundação e a sociedade, influenciando também na revisão dos programas acadêmicos oferecidos pela instituição.

A FGV tem uma estrutura institucional de destaque como importante instituição formadora de quadros que colabora para seu protagonismo em disponibilizar pesquisas e realizar eventos. Geralmente, tais eventos corroboram a argumentação sobre o que se espera de uma gestão

${ }^{12}$ Mais informações disponíveis em: https://ebape.fgv.br/conselho-alumni. Acesso em: 7 fev. 2021.

Práxis Educativa, Ponta Grossa, v. 16, e2118297, p. 1-18, 2021

Disponível em: <https:// revistas2.uepg.br/index.php/praxiseducativa> 
pública, desenvolvida para a excelência em gestão e administração das escolas. Tendem sempre a reafirmar que o Brasil precisa garantir o direito à aprendizagem e, para isso, os professores precisam de formação, uma vez que as licenciaturas não conseguem entregar um profissional apto a lidar com as demandas do nosso tempo, explícito na fala de Claudia Costin (2019) em evento. Em entrevista, Claudia Costin (2019) defende ainda que não importa o quão "boa" seja uma proposta - se não for implementada corretamente pelos professores, não será possível atingir os resultados pretendidos. Esses eventos, mais as mobilizações nas páginas e nas redes das instituições, fazem com que a FGV possa ser identificada como uma instituição atuante na significação da BNCC.

Seguimos então os movimentos dessa instituição nas redes sociais de forma a montar uma rede a partir da FGV e, com base nessa rede, tentar entendermos os movimentos dessa instituição na política de currículo. Essa rede foi construída com auxílio do software NodeXL, alimentado com informações extraídas de páginas da Internet e mídias sociais da FGV e dos seus parceiros.

Identificamos atores sociais importantes, nome dos eventos, movimentos, fundações, todos de algum modo vinculados à FGV. Também mapeamos as parcerias que a FGV vem estabelecendo a fim de vender soluções para implementação da BNCC.

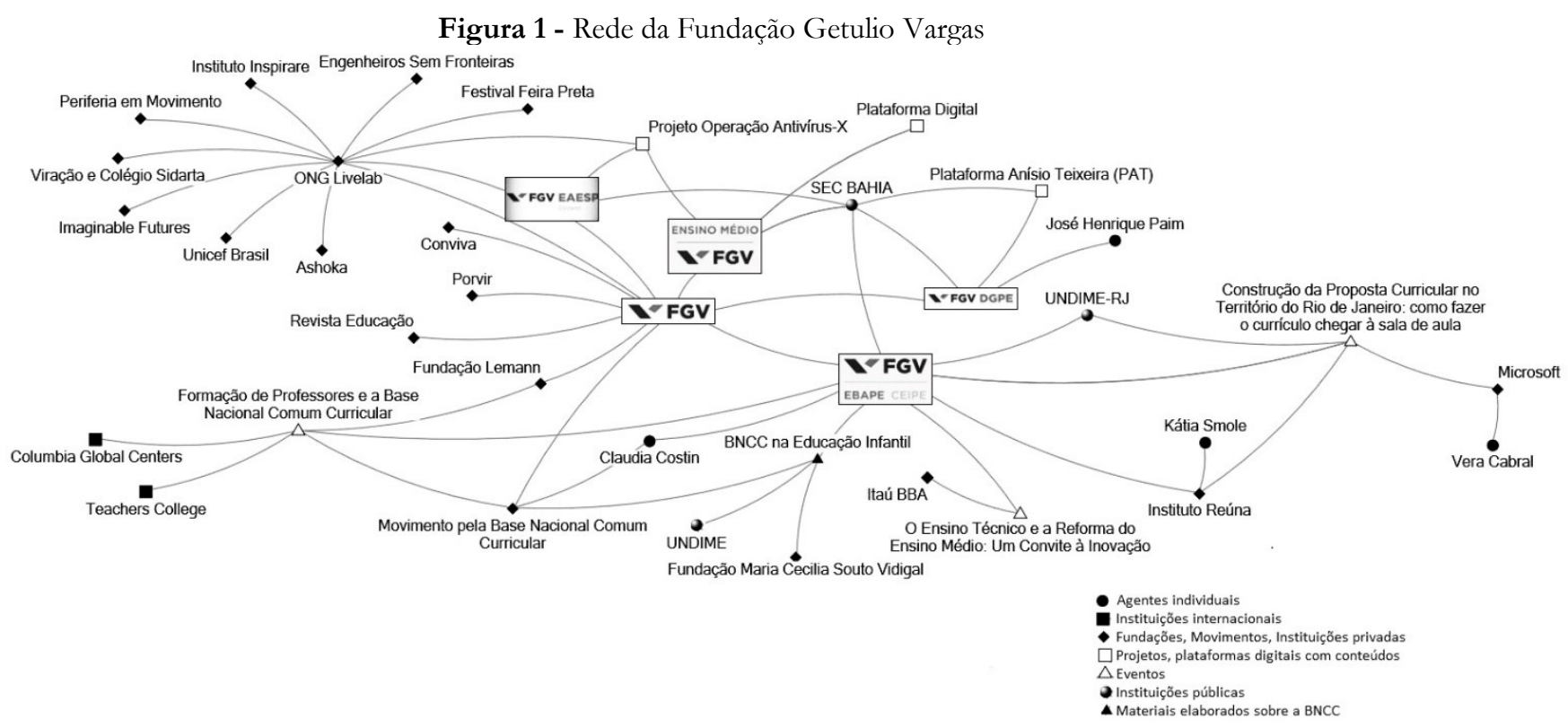

Fonte: Elaborada pelas autoras com auxílio do software NodeXL.

A partir dessa rede, é possível identificarmos a FGV como uma instituição que envolve os seus diferentes departamentos na articulação com o setor público, privado e filantrópico. $\mathrm{O}$ envolvimento com nomes importantes para filantropia no Brasil, tais como Fundação Lemann, Instituto Inspirare, Fundação Maria Cecilia Souto Vidigal, Instituto Reúna e Porvir, demonstra sua capacidade de se relacionar com nomes importantes para as políticas públicas educacionais. Ao realizar eventos, a instituição convidou pessoas com currículo envolvido na promoção de políticas públicas, tais como Vera Cabral, Kátia Smole e José Henrique Paim. Essa explanação inicial faznos considerar que a FGV está expandindo suas relações e aumentando a sua rede de influência por meio da propagação de think tanks.

A partir do CEIPE, são organizados os principais movimentos acerca dos estudos sobre políticas públicas. A FGV igualmente realizou e esteve presente em eventos que apoiam a Base, demonstrando um interesse na sua implementação. Em março de 2018, houve um evento sobre a formação de professores e a BNCC, realizado em parceria com a Columbia Global Centers, Teachers

Práxis Educativa, Ponta Grossa, v. 16, e2118297, p. 1-18, 2021 
College da Columbia University e o CEIPE da FGV: o Encontro sobre formação de professores e a Base Nacional Comum Curricular (BNCC). Segundo informações na página, "[...] foi uma oportunidade para compartilhar aprendizados, desafios e oportunidades para a implementação da política pública em todas as escolas do país" (FUNDAÇÃO LEMANN, 2019, n.p.). A plateia contou com mais de 300 participantes, além de transmissão ao vivo pela Internet. Nesse evento, a fundação anunciou:

[...] desde 2013 nós apoiamos e colaboramos com o Teachers College, Faculdade de Educação da Universidade de Columbia. Nesta quarta-feira, anunciamos nossa nova parceria durante um evento especial sobre "Formação de Professores e a Base Nacional Comum Curricular”. (FUNDAÇÃO LEMANN, 2019, n.p.).

Dia 31 de outubro de 2019, a FGV e o Itaú BBA ofereceram uma palestra sobre "O Ensino Técnico e a Reforma do Ensino Médio: Um Convite à Inovação”. Esse evento foi realizado pelo CEIPE, em parceria com o Itaú BBA, e teve como objetivo mostrar caminhos para implementação do itinerário formativo da educação tecnológica dentro da reforma do Ensino Médio, apresentando casos nacionais e internacionais.

O CEIPE também está envolvido com a venda de pacotes para o setor público. Em consonância com o que Costin (2019) defendeu em sua entrevista, a preocupação é com a capacitação de professores, como pode ser lido para o caso do Estado da Bahia:

A capacitação dos professores baianos das redes estadual, municipais e privadas para
aplicação e adaptação à nova Base Nacional Comum Curricular (BNCC) será feita a partir
de uma parceria entre a Secretaria de Educação (SEC), Fundação Getúlio Vargas (FGV)
e as universidades estaduais. [...]. O secretário de Educação da Bahia, Jerônimo
Rodrigues, exaltou a parceria com as entidades e o processo de capacitação. "Os
professores que estão aí, que foram formados ao longo dos tempos, não estão com
conteúdo atualizado para essa nova base. Então nós temos que preparar os professores
para que eles possam adequar o conteúdo ao que a nova BNCC está propensa”, ressaltou
Jerônimo ao Bahia Notícias. (LEIRO; COELHO, 2019, n.p.).

No movimento dessas instituições privadas, visando oferecer materiais que divulguem a proposta em questão, Kátia Stocco Smole, do Instituto Reúna, também focalizou a formação de professores como garantidora de uma boa implementação da base durante o evento "Construção da Proposta Curricular no Território do Rio de Janeiro", da FGV:

"A formação do educador é o que fará com que o currículo se concretize na sala de aula", disse Kátia Stocco Smole, diretora do Instituto Reúna. [...]. Ter orientações pedagógicas neste momento é essencial para que o documento seja implementado na prática. "[No entanto], o foco das formações não deve ser pedir pros educadores lerem a Base ou o currículo exaustivamente", disse Kátia. Para ela, é preciso usar diferentes estratégias ao explorar a transposição do currículo para a prática para que a formação se reverbere na sala de aula. "A publicação 'Formação Continuada de Professores: contribuições da literatura baseada em evidências', elaborada pela Fundação Carlos Chagas, analisou a eficiência da formação continuada. Estão citados os seguintes caminhos: foco no conhecimento pedagógico, participação coletiva, duração prolongada, métodos ativos de aprendizagem e coerência" (CONVIVA EDUCAÇÃO, 2019, n.p.).

A pandemia da Covid-19, iniciada em 2020 e que permanece no presente ano, levou vários estados a instituírem a educação remota. No Webinário - Regulação e Gestão Educacional durante a Emergência de Saúde Pública, o Conselho Nacional de Educação (CNE) anunciou que a BNCC deve servir de bússola neste momento em que se está lidando com novos modos de pensar a educação escolar. Tais orientações na pandemia também impactaram nas políticas de implementação da BNCC por parte das instituições privadas e filantrópicas. De maneira rápida, foram então divulgadas notícias reafirmando a importância da BNCC neste momento de

Práxis Educativa, Ponta Grossa, v. 16, e2118297, p. 1-18, 2021

Disponível em: <https:// revistas2.uepg.br/index.php/praxiseducativa $>$ 
distanciamento social, com a pretensão de garantir os conhecimentos a serem desenvolvidos pelos docentes.

Durante o período da pandemia, a FGV também vem apresentando Webconferências ${ }^{13}$, no sentido de reiterar a importância das competências e seu foco no desenvolvimento da Educação Infantil. Por meio de webconferência, foi realizada em abril de 2020, uma reunião para apresentar a plataforma FGV Ensino Médio, recurso digital de aprendizagem disponibilizado aos alunos e docentes em trabalho remoto. Essa plataforma oferece conteúdos previstos para a Educação Básica e cursos na área de Gestão Educacional. $\mathrm{O}$ acesso ao conteúdo é realizado mediante um cadastro, para alunos e docentes de escolas parceiras do projeto. Aos estudantes é oferecido o curso "Garanta sua vaga em uma universidade com o melhor material de estudos gratuito para o Ensino Médio", enquanto aos docentes é oferecido o material "Ganhe tempo produzindo e corrigindo provas com avaliações digitais para suas turmas” (ENSINO MÉDIO DIGITAL, 2020, n.p.).

Outra ação foi a disponibilização da Plataforma Anísio Teixeira (PAT) ${ }^{14}$ desenvolvida pela Secretaria da Educação do Estado da Bahia, em parceria com outras secretarias municipais baianas e a FGV. Por meio dessa plataforma, são oferecidos cursos gratuitos para auxiliar os professores durante a pandemia. Os conteúdos envolvem jogos, vídeos, aulas, sugestão de atividades.

Outra ação que inclui a FGV é a junção entre "A Jornada X”, criada pela Organização NãoGovernamental (ONG) Livelab ${ }^{15}$, e o Centro de Empreendedorismo e Novos Negócios da Escola de Administração de Empresas de São Paulo da Fundação Getulio Vargas (FGVCenn). A ação envolveu a criação de um jogo sobre as problemáticas relacionadas à pandemia. Nomeado "Operação Antivírus", os jogadores têm de "solucionar problemas sociais", como uma doença que se dissemina rapidamente e exige dos estudantes pensarem em soluções. Segundo reportagem: "O jogo criado em apenas cinco dias e destinado a jovens de 12 a 25 anos, visa compor um cenário de ajuda no enfrentamento do novo coronavírus" (OPERAÇÃO..., 2020, n.p.).

Ao mesmo tempo em que a FGV apoia o setor filantrópico e privado, se engajando em movimentos e parcerias, tem expandido suas ações com o setor público por meio das Secretarias de Educação. Essas ações não foram identificadas em período anterior às discussões que sucederam a homologação da BNCC, permitindo a conclusão de que essa homologação impulsionou para que essa e outras instituições se aproximassem das Secretarias de Educação.

\footnotetext{
${ }^{13}$ Em 14 de julho, apresentaram Webinar Educação Infantil no contexto da pandemia. Em 9 de julho, Webinar Desenvolvendo Competências na Sociedade Digital. Em 14 de maio, Webinar Como enfrentar os desafios logísticos das Secretarias durante e pós a pandemia. Em 23 de julho, Webinar Perspectivas dos concluintes do ensino médio no contexto da pandemia. Em 23 de junho, Webinar Os efeitos da pandemia sob a ótica dos docentes. Em 30 de junho, Webinar Efeito da pandemia no financiamento da educação. Em 9 de julho, Webinar Desenvolvendo Competências na Sociedade Digital. Em 30 de abril, Webinar Caminhos da Educação Básica em virtude da Covid-19. Em 11 de maio, Webinar Os Impactos da Covid-19 sobre a Educação e o Aumento das Desigualdades. Em 21 de maio, Webinar Planejamento da retomada das aulas. Em 24 de maio, Bate-Papo FGV: Desafios para a Educação Infantil, com Claudia Costin. Em 3 de julho, Webinar Educação a Distância: Desafios e Tendências. Em 7 de maio, Webinar Educação mediada por tecnologia em tempos de pandemia. Todos disponíveis no canal da FGV: https://www.youtube.com/channel/UC8DhN1cJi0QklBQot5hv_kg. Acesso em: 17 ago. 2020.

${ }^{14}$ Disponível em: http://pat.educacao.ba.gov.br/. Acesso em: 17 ago. 2020.

15 A Livelab é uma organização sem fins lucrativos, que se apresenta como um laboratório vivo de inovação social, capaz de desenvolver e aplicar tecnologias e estratégias de jogos colaborativos para a transformação positiva. A instituição afirma também ter o intuito de promover meios que despertem e libertem o espírito criativo e empreendedor de indivíduos e comunidades para que promovam iniciativas de transformação local e inspirem outros e outras realidades a replicarem essa prática, contribuindo, assim, para um impacto em escala. O cofundador é Edgard Gouveia Júnior, considerado o idealizador do movimento.
}

Práxis Educativa, Ponta Grossa, v. 16, e2118297, p. 1-18, 2021 Disponível em: <https:// revistas2.uepg.br/index.php/praxiseducativa $>$ 


\section{Conclusões}

A governança por nós discutida está relacionada à governamentalidade em Foucault. Concordamos com Ball (2013) quando ele menciona existir um silêncio teórico em torno das questões de contestação aos discursos de governamentalidade. As instituições públicas e privadas vêm operando de modo a subjetivar atores sociais da educação, constituindo um modo de governar o currículo. Tais modos se conectam à forma como nos relacionamos com nossa prática profissional e tendem a assegurar como lidamos com o poder. Concordando com Ball que "Não fazemos política, a política nos faそ" (BALL, 2015, p. 2, grifo do autor, tradução nossa), os discursos formam regimes de verdade e constituem as identidades políticas.

Nesse processo, são constituídas ações para regular a tradução da política curricular, tentando frear as imprevisíveis possibilidades de interpretação dos textos curriculares. Tais discursos que governam o currículo são produzidos em redes, movidas por ações, que envolvem pontos de contato, atores empresariais privados e filantrópicos na educação. Os discursos forjam identificações dos professores nas escolas como incapazes de lidar com as mudanças curriculares, justificando, assim, que as instituições invistam para que o currículo seja traduzido do modo suposto como almejado para um dado projeto social. Por sua vez, tal projeto é suposto como consensuado sem conflitos, em nome da "melhoria" da educação brasileira.

Neste artigo, propusemo-nos a identificar uma ampla rede de apoio à política de centralidade curricular e formação docente, vinculada à BNCC, destacando as ações da FGV. Procuramos argumentar haver um protagonismo dessa instituição nos processos de implementação da BNCC, associados às mudanças dos modos de governança nas políticas educacionais. Consideramos esse destaque importante, visando a argumentar não existir um único centro nessa ampla rede política, tal como as investigações que destacam as ações da Fundação Lemann poderiam nos levar a concluir.

Os discursos aos quais FGV está vinculada fazem parte desses processos de governança que mobilizam a política educacional. Por meio da implementação da BNCC, a FGV tem consolidado seu projeto de gestão educacional e de influência sobre as políticas públicas. Em 2021, a FGV foi classificada na Global Go To Think Tank Index Report (MCGANN, 2021), pela Universidade da Pensilvânia, Estados Unidos, como a terceira think tank mais importante do mundo em resposta à Covid-19. O reconhecimento internacional da FGV, como uma instituição influente no Brasil e no mundo nas soluções para os problemas globais, reitera a importância de mais pesquisas sobre as suas ações na política educacional brasileira. Nessa constatação do grande destaque dessa instituição que, ao contrário de outras instituições frequentemente citadas por suas ações nas políticas educacionais, tem longa e significativa tradição acadêmica, com formação de importantes quadros no país, importa entendermos a capilarização de discursos em defesa da centralidade curricular e a constituição de políticas muito além do Estado.

Tais instituições, com seu poder reforçado pela atuação em redes políticas, vão cada vez mais intensificando e capilarizando o discurso de que nem o poder público, nem as escolas, nem as Universidades têm competência técnica para "resolver" os problemas educacionais. Sua atuação seria, assim, benéfica, em prol do interesse da nação e da melhoria da qualidade da educação brasileira. Nesses processos discursivos, são apagadas as contingências que viabilizaram a constituição desse discurso de competência técnica, dentre elas a de ser sustentado por um diagnóstico de má qualidade da educação brasileira construído sob as mesmas bases, e, por vezes, pelos mesmos atores sociais, que apresentam as "soluções para os problemas educacionais".

Neste artigo, queremos destacar um aspecto especificamente curricular, associado à atuação de instituições privadas e filantrópicas como think tanks educacionais. A forma de atuação dessas

Práxis Educativa, Ponta Grossa, v. 16, e2118297, p. 1-18, 2021

Disponível em: <https:// revistas2.uepg.br/index.php/praxiseducativa $>$ 
instituições, no que tange ao currículo, vem sendo cada vez mais voltada à elaboração de modelos pré-definidos que não apenas auxiliam o trabalho docente, mas podem reduzir sua atuação à etapa de aplicação. Como pode ser identificado no caso das propostas da FGV - mas não apenas nelas -, o docente é significado como o parceiro a ser "ajudado", porque sua formação é deficitária, porque os textos das propostas curriculares são muito longos, as condições de trabalho são ruins, as dificuldades, pressupostas, mas não evidenciadas, são enormes.

Não se trata aqui de negar dificuldades do trabalho docente, tampouco de assumir uma postura romântica na relação com a docência. Buscamos diferentemente salientar o quanto tais afirmações são reiteradas como truísmos, tendendo a homogeneizar realidades contextuais díspares e invisibilizar práticas de sucesso. Igualmente podem desempoderar os agentes de construção de qualquer currículo - docentes e estudantes. Especialmente se entendemos currículo como um texto sem significado pré-definido, com sentidos sempre negociados em práticas contextuais da instituição escolar, o tensionamento dessas ações partir de outras pesquisas pode contribuir para redefinir as orientações prevalentes.

Salientamos que esse quadro pode se tornar ainda mais problemático se considerarmos o cenário de investimentos na educação remota, em atividades síncronas e assíncronas, acelerado pela pandemia da Covid-19, e a forte desvalorização das instituições públicas, desenvolvida por discursos ultraconservadores e negacionistas (LOPES, 2021). Investigarmos a formas de atuação dessas redes políticas, o caráter prescritivo de suas proposições, a opacidade entre o público e o privado, e as novas formas de governança que nos fažem politicamente vêm se mostrando, para nós, uma agenda urgente na tentativa de desconstruir a hegemonia de tais discursos.

\section{Referências}

AGUIAR, M. A. S. Política educacional e a base nacional comum curricular: o processo de formulação em questão. Currículo sem Fronteiras, [s. l.], v. 18, n. 3, p. 722-738, set./dez. 2018.

AVELAR, M.; BALL, S. J. Mapping new philanthropy and the heterarchical state: the mobilization for the national learning standards in Brazil. International Journal of Educational Development, [s. l.], v. 64, p. 65-73, 2017. DOI: https://doi.org/10.1016/j.ijedudev.2017.09.007

AVELAR, M.; NIKITA, D. P.; BALL, S. F. Education policy networks and spaces of 'meetingness': a network ethnography of a Brazilian Seminar. In: ALTINYELKEN, H. K. (org.). Global education policy and international development: new agendas, issues and policies. London: Bloomsbury, 2018. p. 55-74.

BALL, S. J. Neoliberal education, neoliberal research and truth-telling. In: SEMINÁRIO DIÁLOGOS COM A PESQUISA - As contribuições de Stephen Ball para a pesquisa educacional no contexto brasileiro: análises e reflexões, 2013. Campinas. Conferência [...]. Campinas: Unicamp, 2013. Disponível em: https://fe-old.fe.unicamp.br/ead/galerias/4030/4026. Acesso em: 22 set. 2020.

BALL, S. J. Educação Global S.A.: novas redes políticas e o imaginário neoliberal. Tradução Janete Bridon. Ponta Grossa: UEPG, 2014.

BALL, S. J. What is policy? 21 years later: reflections on the possibilities of policy research. Discourse: Studies in the Cultural Politics of Education, [s. l.], v. 36, n. 3, p. 306-313, 2015. DOI: https://doi.org/10.1080/01596306.2015.1015279

Práxis Educativa, Ponta Grossa, v. 16, e2118297, p. 1-18, 2021 
BALL, S. J.; BOWE, R. Subject departments and the "implementation" of National Curriculum policy: an overview of the issues. Journal of Curriculum Studies, London, v. 24, n. 2, p. 97-115, 1992. DOI: https://doi.org/10.1080/0022027920240201

BALL, S. J.; JUNEMANN, C. Networks, new governance and education. Chicago: The Policy Press, 2012.

BALL, S. J.; MAGUIRE, M.; BRAUN, A. Como as escolas fazem as políticas: atuação em escolas secundárias. Tradução Janete Bridon. Ponta Grossa: Editora UEPG, 2016.

BANCO MUNDIAL. Relatório sobre o desenvolvimento mundial de 2018: Aprendizagem para realizar a promessa da educação. 2018. Disponível em: https://openknowledge.worldbank.org/bitstream/handle/10986/28340/211096mmPT.pdf?sequ ence $=28$ \&isAllowed $=$ y. Acesso em: 20 ago. 2020 .

BRASIL. Plano Nacional de Educação PNE 2014-2024: Linha de Base. Instituto Nacional de Estudos e Pesquisas Educacionais Anísio Teixeira. Brasília: Inep, 2014. Disponível em: http://pne.mec.gov.br/. Acesso em: 20 ago. 2020.

BRASIL. Base Nacional Comum Curricular. Versão Final, 2018. Brasília: Ministério da Educação. Disponível em: https://bit.ly/3rgl1IX. Acesso em: 22 set. 2019.

CONVIVA EDUCAÇÃO. Formação continuada para a BNCC. Rio de Janeiro, 2019. Disponível em: https://gestaoescolar.org.br/conteudo/2282/formacao-continuada-para-a-bncc. Acesso em: 17 mar. 2021.

CÓSSIO, M. F.; SCHERER, S. S. Governança e redes políticas educacionais: um estudo sobre o Estado do Rio Grande Do Sul - RS. Teoria e Prática da Educação, Maringá, v. 21, n. 3, p. 137 149, set./dez. 2018. DOI: https://doi.org/10.4025/tpe.v21i3.45417

COSTIN, C. FGV EBAPE/CEIPE - Construção da proposta curricular no território do Rio de Janeiro. Canal FGV YouTube, 2019. 1 vídeo (2h07min47seg). Disponível em: https://www.youtube.com/watch?v=8t3NilldzvY. Acesso em: 24 set. 2020.

DIAS, R. E. D.; LOPES, A. C. Sentidos da prática nas políticas de currículo para formação de professores. Currículo sem Fronteiras, [s. l.], v. 9, n. 2, p. 79-99, jul./dez. 2009.

ENSINO MÉDIO DIGITAL. Sistema de avaliação customizável preparatório para o Enem. 2020. Disponível em: https://ensinomediodigital.fgv.br. Acesso em: 12 dez. 2020.

OPERAÇÃO Antivírus: jogo estimula jovens a combater o Covid-19 sem sair de casa. Folha/UOL, São Paulo, 2020. Disponível em: https://bit.ly/2UJtybg. Acesso em: 20 ago. 2020.

FUNDAÇÃO LEMANN. Encontro sobre formação de professores e a BNCC. 2019. Disponível em: https://fundacaolemann.org.br/noticias/encontro-sobre-formacao-deprofessores-e-a-bncc. Acesso em: 5 fev. 2020.

LACLAU, E. La razón populista. Buenos Aires: Fondo de Cultura Económica, 2009.

LACLAU, E. Emancipação e diferença. Rio de Janeiro: EdUERJ, 2011.

LEIRO, M.; COELHO, J. SEC firma parceria com Fundação Getulio Vargas para formação de professores na BNCC. Bahia Notícias, Salvador, 29 out. 2019. Disponível em: 
https://www.bahianoticias.com.br/noticia/240871-sec-firma-parceria-com-fundacao-getuliovargas-para-formacao-de-professores-na-bncc.html. Acesso em: 17 mar. 2021.

LIMA, I.; HYPÓLITO, A. Escola Sem Partido: análise de uma rede conservadora na educação. Práxis Educativa, Ponta Grossa, v. 15, e2015290, p. 1-17, 2020. DOI: https://doi.org/10.5212/praxeduc.v.15.15290.053

LÔBO, C. OCDE: Guedes diz que Brasil já sabia ser o 'número 2' na fila por apoio dos EUA. G1, 10 out 2019. Disponível em: https://g1.globo.com/politica/blog/cristianalobo/post/2019/10/10/ocde-guedes-diz-que-brasil-ja-sabia-ser-o-numero-2-na-fila-por-apoiodos-eua.ghtml. Acesso em: 15 set. 2020.

LOPES, A. C. Por um currículo sem fundamentos. Linhas Críticas, Brasília, v. 21, n. 45, p. 445466, 2015. DOI: https://doi.org/10.26512/lc.v21i45.4581

LOPES, A. C. Políticas de currículo em um enfoque discursivo: notas de pesquisa. In: LOPES, A. C.; OLIVEIRA, A. L. A. R.; OLIVEIRA, G. G. S. (org.). A teoria do discurso na pesquisa em educação. Recife: Editora UFPE, 2018. p. 133-168.

LOPES, A. C. Radical investment in the curriculum in times of Covid-19: Can we question the anti-science discourses? Prospects, Paris, p. 1-8, 2021. DOI: https://doi.org/10.1007/s11125$\underline{021-09548-8}$

LOPES, A. C.; MACEDO, E. Contribuições de Stephen Ball para o estudo de políticas de currículo. In: BALL, S., MAINARDES, J. (org.). Políticas educacionais: questões e dilemas. Volume 1. São Paulo: Cortez, 2011. p. 249-283.

LOPES, A. C.; MACEDO, E. Apresentação: Uma alternativa às políticas curriculares centralizadas. Revista Roteiro, Joaçaba, v. 46, p. 1-9, jan./dez. 2021. DOI: https://doi.org/10.18593/r.v46i.27181

MACEDO, E. Base Nacional Curricular Comum: novas formas de sociabilidade produzindo sentidos para educação. Revista e-Curriculum, São Paulo, v. 12, n. 3, p. 1530-1555, out./dez. 2014.

MATHEUS, D. S.; LOPES, A. C. Sentidos de qualidade na Política de Currículo (2003-2012). Educação \& Realidade, Porto Alegre, v. 39, n. 2, p. 337-357, abr./jun. 2014. DOI: https://doi.org/10.1590/s2175-62362014000200002

MCGANN, J. G. “2020 Global Go To Think Tank Index Report” (2021). TTCSP Global go to think tank index reports. 18, 2021. Disponível em: https://repository.upenn.edu/think_tanks/18. Acesso em: 10 mar. 2021.

MOUFFE, C. Sobre o político. São Paulo: WMF Martins Fontes, 2015.

PEREDA, C. Fundaciones privadas en la educación media pública de Uruguay. Arquivos Analíticos de Políticas Educativas, [s. l.], v. 27, n. 150, p. 1-27, 2019. DOI: https://doi.org/10.14507/epaa.27.3562

REPUlHO, C. Apresentação de painel sobre a BNCC. Seminário Construção da proposta curricular no território do Rio de Janeiro. Canal FGV EBAPE/CEIPE Youtube, 2019. 1 vídeo (2h07min47seg). Disponível em: https://www.youtube.com/watch?v=8t3NilldzvY. Acesso em: 20 ago. 2020. 
RIVZI, F.; LINGARD, B. Políticas educativas en un mundo globalizado. Vigo: Educación, 2013.

ROSA, L. O.; FERREIRA, V. S.; SILVA, S. C. V. Elaboração e análise de redes de política. Revista de Estudios Teóricos y Epistemológicos en Política Educativa, Ponta Grossa, v. 5, e2014421, p. 1-12, 2020. DOI: https://doi.org/10.5212/retepe.v.5.14421.001

TARLAU, R. MOELLER, K. 'Philanthropizing' consent: how a private foundation pushed through national learning standards in Brazil. Journal of Education Policy, [s. l.], v. 35, n. 3, p. 337-366, 2019. DOI: https://doi.org/10.1080/02680939.2018.1560504

VERGER, A. A política educacional global: conceitos e marcos teóricos chave. Práxis Educativa, Ponta Grossa, v. 14, n. 1, p. 9-33, jan./abr. 2019. DOI: https://doi.org/10.5212/praxeduc.v.14n1.001

WAN, T. O que Bill Gates aprendeu sobre educação em 17 anos - e por que vai investir mais US\$ 1,7bi. Porvir, 20 out. 2020. Disponível em: https://porvir.org/bill-gates-aprendeu-sobreeducacao-em-17-anos-por-vai-investir-mais-us-1-7-bi/. Acesso em: 19 ago. 2020.

YOUNG, M. Construindo uma Base Curricular Comum. Canal Movimento pela Base YouTube, 2014. 1 vídeo (31min36seg). Disponível em: https://www.youtube.com/watch?v=Q9ZH4AcW0y0. Acesso em: 17 mar. 2021.

Recebido em 09/04/2021

Versão corrigida recebida em 14/07/2021

Aceito em 15/07/2021

Publicado online em 19/07/2021 